\title{
Experiences and expectations of obese older people on the care received in the primary health care network
}

\author{
Experiências e expectativas de idosos com obesidade sobre a assistência na atenção primária à saúde \\ Experiencias y expectativas de ancianos obesos sobre la asistencia en atención primaria de salud
}

Renata Evangelista Tavares Machado' ORCID: 0000-0001-9004-3941

Maria Cristina Pinto de Jesus" ORCID: 0000-0002-8854-690X

Vanessa Augusta Souza Braga' ORCID: 0000-0001-6714-9318

Daniel Rodrigues Machado'"' ORCID: 0000-0003-1255-7693

Deíse Moura de Oliveira'v ORCID: 0000-0003-3804-7413

Miriam Aparecida Barbosa Merighi' ORCID: 0000-0002-9705-2557

'Universidade de São Paulo. São Paulo, São Paulo, Brazil. "Universidade Federal de Juiz de Fora. Juiz de Fora, Minas Gerais, Brazil.

I'Prefeitura Municipal de Astolfo Dutra. Astolfo Dutra, Minas Gerais, Brazil.

"v Universidade Federal de Viçosa. Viçosa, Minas Gerais, Brazil.

How to cite this article:

Machado RET, Braga VAS, Machado DR, Jesus MCP, Oliveira DM, Merighi MAB. Experiences and expectations of obese older people on the care received in the primary health care network. Rev Bras Enferm. 2020;73(Suppl 3):e20200438. doi: http://dx.doi.org/10.1590/0034-7167-2020-0438

Corresponding author: Renata Evangelista Tavares Machado E-mail: renataunirio@yahoo.com.br

EDITOR IN CHIEF: Antonio José de Almeida Filho ASSOCIATE EDITOR: Ana Fátima Fernandes

Submission: 06-18-2020

Approval: 08-26-2020

\section{ABSTRACT}

Objective: to understand the experiences and expectations of obese elderly people on the care they received in the primary health care network. Methods: phenomenological study, in which 16 obese elderly people living in a municipality in the state of Minas Gerais, Brazil, were interviewed. Their statements were organized into categories and analyzed according to Alfred Schütz's social phenomenology and thematic literature. Results: the following categories emerged: "Care neglected to obese elderly people in the primary health care network", "Group activities as a way to provide primary health care to obese elderly people: a present past", and "Qualified longitudinal care, centered in the needs of obese elderly people". Final considerations: offering comprehensive and longitudinal primary health care to obese older people was difficult, and there was instability in the consolidation of public policies, which pointed out the need for effective bonds between different healthcare network services and between professionals and users.

Descriptors: Aged; Obesity; Primary Health Care; Nursing; Qualitative Research.

\section{RESUMO}

Objetivo: compreender as experiências e expectativas de pessoas idosas com obesidade relacionadas à assistência prestada no âmbito da Atenção Primária à Saúde. Métodos: pesquisa fenomenológica que entrevistou 16 idosos com obesidade de um município de Minas Gerais, Brasil. Os depoimentos foram organizados em categorias e analisados segundo a fenomenologia social de Alfred Schütz e literatura temática. Resultados: emergiram as categorias: "O cuidado negligenciado à pessoa idosa com obesidade na Atenção Primária à Saúde", "Atividades grupais como um modo de assistir pessoas idosas com obesidade na Atenção Primária à Saúde: um passado presente" e "Assistência longitudinal qualificada e centrada nas necessidades da pessoa idosa com obesidade". Considerações finais: o atendimento integral e longitudinal ao idoso com obesidade na Atenção Primária à Saúde é dificultoso, existindo instabilidade na consolidação de políticas públicas, sinalizando a necessidade de vínculos efetivos entre os serviços da rede de atenção à saúde e entre profissionais e usuários.

Descritores: Idoso; Obesidade; Atenção Primária à Saúde; Enfermagem; Pesquisa Qualitativa.

\section{RESUMEN}

Objetivo: Comprender experiencias y expectativas de ancianos con obesidad relativas a la asistencia brindada en Atención Primaria de Salud. Métodos: Investigación fenomenológica entrevistándose 16 ancianos con obesidad de un municipio de Minas Gerais, Brasil. Los testimonios fueron organizados en categorías y analizados según fenomenología social de Alfred Schütz y literatura temática. Resultados: Surgieron las categorías "La atención negada al anciano con obesidad en Atención Primaria de Salud","Actividades grupales como modo de atender ancianos con obesidad en Atención Primaria de Salud: un pasado presente" $y$ "Atención longitudinal calificada y centrada en las necesidades del anciano con obesidad". Consideraciones finales: La atención integral y longitudinal del anciano con obesidad en Atención Primaria de Salud es dificultosa, existiendo inestabilidad en la consolidación de políticas públicas, señalando esto la necesidad de vínculos efectivos entre los servicios de la red de atención de salud y entre profesionales y usuarios.

Descriptores: Anciano; Obesidad; Atención Primaria de Salud; Enfermería; Investigación Cualitativa. 


\section{INTRODUCTION}

Population aging has been progressing, and estimates indicate that the number of older people will continue to grow worldwide. The global population aged over 60 years was estimated to be 841 million people, and must reach two billion people in $2050^{(1)}$. This has been celebrated, because it is seen as the result of a set of successful efforts, including reduction in early mortality and fertility rates, with the latter factor associated with vaccinepreventable, infectious, and parasitic diseases.

This phenomenon is followed by an epidemiological change that imparts a higher comorbidity load to chronic conditions. In Brazil, these health problems were responsible for $74 \%$ of overall deaths and $17 \%$ of premature deaths recorded in $2019^{(2)}$, which poses a remarkable challenge to public health and requires proper responses from health services. Investing in health services is critical to improving the follow-up of chronic conditions, which includes strengthening health systems and the training and offer of qualified human resources ${ }^{(3)}$.

Among the most prevalent chronic diseases, obesity stands out. A study that analyzed the prevalence of this health problem in 195 countries identified that the number of cases has doubled in 70 of these countries since $1980^{(4)}$. Obesity in older people can contribute to the development of osteoarthritis and systemic hypertension ${ }^{(5)}$, postural instability ${ }^{(6)}$, and physical disability ${ }^{(7)}$, in addition to increasing the chances of developing depression ${ }^{(8)}$, having a negative body image, and experiencing guilt, shame, humiliation, and low self-esteem ${ }^{(9)}$.

From a collective perspective, obesity in the older population will have consequences on health systems globally, because it will result in the need for high amounts of resources to pay for long-term treatments ${ }^{(10)}$. A study carried out in Germany showed that the cost and use of health services are greater in the group of older people with excess weight compared to those in age groups with younger people(11).

In Brazil, primary health care (PHC) assists people in all the phases of the life cycle and is the sphere responsible for coordinating care, especially that related to chronic diseases. However, nurses that work at this care level still have difficulties to design actions oriented toward obese people ${ }^{(12)}$.

Care to obese older people is an even greater challenge, because of the possibility of the coexistence of multiple comorbidities associated with aging. Therefore, it is assumed that, to offer care targeting this population, nurses or other professionals must have technical and scientific knowledge, in combination with accumulated experiences, to encompass older people's different dimensionalities in the proposed actions and encourage the development of bonds and co-responsibility in the care process ${ }^{(13)}$.

This type of care must go beyond drug prescriptions and an excessive number of interventions and value dialogue and intersubjectivity in the social relationship between professionals and obese older people. Therefore, the importance of assuming the perspective of valorization of experiences and expectations of the care receiver is justified when professionals are providing health care with resources. In face of the above, the following questions guided the present study: How do obese older people perceive the assistance offered in PHC? Does this perception match the expectations of these older people?
The results of the present study will be able to inform the review of health practices and policies oriented toward the population that lives with this double vulnerability - advanced chronological age and obesity. It is believed that the experiences and expectations of this target population regarding the assistance offered in PHC will bring relevant elements to the design of comprehensive and longitudinal care to these users. The present study will be able to contribute to reflection in general and the development of $\mathrm{PHC}$ practices that meet the health demands originating from the demographic and epidemiological transitions currently happening in society.

\section{OBJECTIVE}

To understand the experiences and expectations of obese older people regarding the assistance they receive in primary health care.

\section{METHODS}

\section{Ethical aspects}

The present study met the ethical principles mentioned in the Brazilian National Health Council Resolution no. 466/2012(14), and its proposal was approved by the human research ethics committee at the public university linked to the execution of the study.

\section{Theoretical-methodological framework}

The present study was based on Alfred Schütz's social phenomenology principles ${ }^{(15)}$. The backbone of this branch is the meaning of actions of people in the social world. Actions can be considered a conscious and intentional conduct, grounded on intersubjective relationships. The "reasons why" are searched for to understand the actions originating in past and present experiences, and the "reasons for" are sought to know the expectations and reasons that drive the actions ${ }^{(15)}$. The present study will show the set of "reasons why" and "reasons for" in the experience of obese older people regarding the assistance offered to them in PHC.

\section{Study type}

This was a phenomenological study, which applied Alfred Schütz's framework. It was carried out according to the steps recommended by the Consolidated Criteria for Reporting Qualitative Research ${ }^{(16)}$.

\section{Methodological procedures}

\section{Study setting}

The setting of the present study was Basic Health Units (BHUs) in a municipality in the interior of the state of Minas Gerais, Brazil, whose population is estimated to be 568,873 people ${ }^{(17)}$. The PHC service network in this municipality was made up of 63 $\mathrm{BHUs}$ spread over seven administrative regions and 12 sanitary regions $^{(18)}$. The share of the general population covered by $\mathrm{PHC}$ was $74.23 \%$, of which $57.47 \%$ received care from the Family Health Strategy (FHS) ${ }^{(19)}$. 


\section{Data source}

The participants of the present study were older people aged over 60 years who met the following inclusion criteria: having class I (from $30 \mathrm{~kg} / \mathrm{m}^{2}$ to $34.9 \mathrm{~kg} / \mathrm{m}^{2}$ ), II (from $35 \mathrm{~kg} / \mathrm{m}^{2}$ to $39.9 \mathrm{~kg} / \mathrm{m}^{2}$ ), or III ( $\left.\geq 40 \mathrm{~kg} / \mathrm{m}^{2}\right)$ obesity; acknowledging themselves as obese people; and living in an area covered by a BHU with FHS activities. It is important to stress that the World Health Organization reference was used in the nutritional screening ${ }^{(20)}$. Older people who could not communicate verbally, could not walk without help, and showed visual deficiency or neurological diseases previously diagnosed were excluded.

\section{Data collection}

Access to older people was obtained after authorization of the Department of Programs and Actions at the Primary Health Care Subsecretariat of the municipality. Once this authorization was given, four BHUs that already had research activities in progress as part of their routine and whose dynamics was based on the FHS perspective were intentionally selected. The FHS facilitated the identification of older people possibly eligible to be interviewed by means of the activities of community health workers in the area.

The next step was reaching out the nurses responsible for the BHUs. After this contact, permission was granted to consult community health workers about the presence of users enrolled in the coverage area who were 60 years old or older and had obesity. Therefore, the approach to older people was carried out with the indication and company of these professionals at the home of the potential participants. When they accepted to be part of the sample, the date, time, and place were defined for the interview to be carried out. A convenience sample was selected from a variable number of interviewed older people per $\mathrm{BHU}$, since the goal was to seek people who experienced the phenomenon under discussion regardless of the region where they lived.

Statement collection was carried out between June and September 2019 by the main researcher, who was a PhD candidate at that time. The instrument applied to collect data was the phenomenological interview, whose face-to-face contact between researcher and interviewee allows data to emerge. In this type of interview, the phenomenon is grasped from the interaction, dialogue, and exchange between these two parts ${ }^{(21)}$. A semi-structured script was used to guide the interview, and it had the following request and question: Tell me about the care you received at the health unit at the neighborhood you live in, taking into account the fact that you are an obese older person; and What type of care do you wish to receive at the health unit to meet your needs, taking into account your age and your obesity situation?. The data collection script also included questions to gather anthropometric, personal, and socioeconomic information.

Before initiating the interview, the researcher clarified the study objectives, the ethical aspects involved, and the need to sign free and informed consent forms to the older people. The body mass index of each participant was calculated after measuring their mass and height by using a portable digital scale and a tape measure, respectively. The researcher asked permission to the older people to use an audio recorder to fully register their statements, which would allow subsequent analysis. The average duration of the interview was 40 minutes.

There were no refusals or withdrawals regarding participating in the present study. The number of participants was not established a priori. Sixteen interviews were conducted and all the statements were included in the study because of the richness of meanings they contained. Data collection was concluded when data meaningful content was reached and new subjects no longer emerged. This was an indication that the study objective was achieved and the questions that guided the study were answered ${ }^{(22)}$.

All the interviews were carried out at the older people's homes, in a private space, restricted to the researcher and the participant, to provide privacy and safety for the older people to verbalize their experiences. The recorded audio was kept in a place that could be accessed by the researcher only. To guarantee the anonymity of the participants, the statements were identified by the letter "I" (for "interview)" followed by an Arabic numeral that indicated the position the interview occupied in the interview sequence.

\section{Data organization and analysis}

Results organization and analysis were based on assumptions described in a theoretical study grounded on Alfred Schütz's social phenomenology ${ }^{(23)}$. First, each transcribed statement was read and reread thoroughly, with an attempt to move away from theory, to value the meanings made explicit by the participants. In a posterior step, organization of the statements and understanding analysis were carried out, and the content was grouped according to meaning similarity, which allowed the definition of thematic categories. The past and present experiences of obese older people regarding the assistance they received in $\mathrm{PHC}$ resulted in the creation of categories related to "reasons why", whereas the tangible expectations resulting from this type of assistance converged into the formation of the category that expressed the "reasons for". Last, results were interpreted from the perspective of social phenomenology and the theoretical framework related to the examined subject.

\section{RESULTS}

The studied group mostly was older women who were married, lived with at least one relative and showed class III obesity, whose age ranged from 60 to 88 years, and with a low level of education (with a prevalence of illiteracy and incomplete middle school). Most of the participants were retired women who received a salary and had a family income of two minimum wages.

\section{Neglected care to obese older people in primary health care (reasons why)}

The reported experiences about the assistance offered by PHC professionals to the study target population reflected the fragility of the actions oriented specifically toward tackling obesity:

My doctorworks at the free clinic. Henever touches on the weight subject, because he does not weigh me. [...]/do not receive proper assistance. You get there and they do not give you even the medication, let alone checkingyour weight. They do not weigh you! They do not do the basic stuff. [...] The clinic offered me nothing to make me lose weight. (I1) 
I have never received any type of guidance to lose weight at the free clinic. [...] Every time I have an appointment at the clinic, previously scheduled, they weigh me and take measures. But the doctor there has never given me any guidance on the weight subject. [...] do not have a weight follow-up [...]. The nurse at the clinic has never said anything about weight, about food to me. [...] you can count the nurses that really help you on the fingers of one hand. (I8)

Although some older people mentioned health practices oriented toward the condition they had, they reported that these practices emerged by means of prescriptive orientations, which introduced the need to lose weight to control other diseases that the examined group had:

He [the physician] can see I cannot walk properly. He says I need to lose weight. Every time I go to the free clinic, they weigh me and measure my height and prick my finger to measure my glycemia. They give me guidance [...]. The doctor at the clinic told me to do aqua aerobics to lose weight and put an end to my knee pain. (16)

Every time I have an appointment with the doctor at the free clinic, they tell me I have to lose weight [...] I think just telling people to lose weight is useless, they have to tell me something I can do to burn the fat in my belly. Give me guidance on a physical exercise that I can do, just telling me to lift weights will not do because I will not be able to do that.. [...] It has to be a guidance on what to do, how to do it [...]. (115)

\section{Group activities as a way to provide assistance to obese older people in primary health care: a present past (rea- sons why)}

When asked about the assistance received in PHC, the interviewed obese older people brought up the group activities oriented toward losing weight and developing healthy habits that were offered at the health units in their neighborhoods in the past and were no longer available when data collection occurred:

What the clinic did was assembling a weight loss group. [...] but this group does not exist anymore, we had no more sessions. [...] it was carried out by the nurse. There were lectures, she would talk to us. [...] And it was a good opportunity to get to know people. Many people lost weight there. [...] The nurse would talk about using sugar [...] there was a snack with diet food. (I2)

When I attended the group meeting at the free clinic, it was nice, but it does not exist anymore. One of the professionals who worked there showed a video about food. It showed that soft drinks are bad for your health, too much salt is bad for your health. It was like a class they gave us. It was nice, but we already know how these things work [...]. They explained several things about food. I liked it. And there are many people that might not know it. (19)

\section{Qualified longitudinal care, centered at the needs of obese older people (reasons for)}

The participants stressed the importance of humanization in the assistance delivered by PHC professionals, who must consider that they are dealing with older people, with an obesity health problem:
I wanted him [the physician] to listen to me, ask me stuff, put me at ease. Not feel stupid. (I10)

The professional should treat us with affection. Because we, people who have weight issues, already are sort of worried [...]. It hurts me to depend so much on other people because of my condition. That is why I want to get better, to become less dependent of other people [...]. (I12)

l expected the doctor to be thoughtful, treat us with kindness, because old age is really a very annoying thing. When you are old, you get very needy. Sometimes, a word can hurt you, and some people [professionals] cannot see that where they are working [...] remember that they can be an older person one day. (113)

Regarding expectations, the obese older people also expressed that $\mathrm{PHC}$ professionals must provide qualified care, with technical competence to act according to the specificities of each case:

The clinic should have a specialized person to provide guidance on weight issues because it is not just me, there are more people needing help. [...] / cannot take these drugs to lose weight. So the professional should find another way. It should be a professional able to offer this guidance, that knew what has to be done to lose weight [...]. (18)

I wanted the doctor at the clinic to provide care like that offered by the health insurance doctor, with advising. And I would follow the diet [...]. (114)

Still in that direction, the interviewed people emphasized the importance of other professionals and resources in $\mathrm{PHC}$ to increase access to actions that favor weight loss:

I wanted the clinic to have [...] physical education professionals to walk with us on Mondays, Wednesdays, and Fridays [...], do physical exercises, make friends, make the experience pleasant [...]. (13)

It would be much easier if the exercises could be done at the clinic. [...] What I wanted the most was to do exercises in the pool, which would help me a lot, but I cannot afford that. [...] It is not available here. I wanted to have the possibility of getting these treatments. (17)

Educational groups stood out among the actions that the older people expected to be offered in PHC. These meetings were considered strengthening spaces to work on the biopsychosocial specificities of the age group under discussion and of obesity:

I felt like doing an activity for my mind too. I think it would help me improve a lot. [...] Crocheting a little in the group sometimes and filling up my mind, because the things that go on in our head influence weight gain a lot. [...] I would go out, get to know more people, communicate more, and thus lose weight. (112)

The service had to give the opportunity for us to have a collective appointment, a group to try to solve this weight issue. Around four, five people on the same day, all of them older people. An effective help group, because there is no point in having a group if it is every man for himself. [...] have union, motivation [...]. Having the professionals' support. (I16) 
Discontinuity in the offered services experienced by the participants encouraged them to regard longitudinal care as an important ally to lose weight in the PHC context and wish for it:

I hope the free clinic offers me a monthly follow-up, checks on my blood pressure, explains stuff about diseases, measures my weight. It would be great for me to have a follow-up. I hope l lose weight, so I am taking the medicine without medical prescription. (14)

The clinic should have some sort of control, either every month or every three months [...]. I wanted to get a closer weight follow-up [...] to know if it is all going well or not. Because you do the stuff, cut out what they say you should not eat or drink, but you cannot know if it is solving the problem because there is no follow-up. (I5)

\section{DISCUSSION}

The results of the present study showed that the experiences of obese older people regarding the assistance they received in $\mathrm{PHC}$ put together past and present situations (reasons why) characterized by negligence in the care provided to this population and discontinuity of group activities previously offered at health units.

The participants verbalized the fragility of actions oriented toward obese older people in this healthcare level, such as intermittence in the measurement of anthropometric parameters. A study carried out in 14 BHUs in the state of São Paulo, Brazil, emphasized the relevant work developed by nursing professionals in the follow-up of anthropometric measures of users, including older people. This study stressed that underestimating or neglecting the population's anthropometric data can originate obesity underreporting in the area and deprive people who need weight follow-up of care ${ }^{(24)}$.

It is acknowledged that providing obese older people with care, taking into account care comprehensiveness, is necessary to overcome the fragilities in the actions. To do that, it is necessary to give patients the obesity diagnosis, which requires awareness-raising of professionals and some material resources (platform scale, preferably with a capacity over 200 kg; vertical stadiometer or inelastic tape measure; calculator; and chart or disk to determine body mass index) ${ }^{(12)}$, in addition to the older people's health history card.

When the health unit has these material resources, the obesity diagnosis can be carried out, and the admission step is the most appropriate time to do that. It is important to analyze some specificities of this population during this step, such as evaluating the autonomy to make food choices and prepare meals and assessing impaired taste and smell, difficulty to chew and swallow food, and ophthalmologic difficulties, which can influence food selection, resulting in alterations in body weight ${ }^{(25)}$.

Obese older people that participated in a study in Barcelona, Spain, reported that health professionals gave them repetitive and superficial recommendations oriented toward weight loss, with prohibitive directions regarding eating that proved insufficient to promote changes in life habits. This result showed that health professionals simplify the complexity of obesity and do not establish a relationship of reciprocity capable of promoting motivation and active engagement of people in their self-care ${ }^{(9)}$.

Approaching people with obesity requires attention by health professionals, given that superficial guidance does not meet the needs and expectations of this group. Obesity during old age entails encouraging practices focused on promoting health, including a healthy diet, moderate physical exercises, and advising.

For the actions targeting obese older people to be carried out with proper quality, it is necessary that health professionals look at older people taking into consideration their knowledge background, their experiences ${ }^{(15)}$ regarding food, and their life habits and combine this set of information with clinical and laboratory data.

Studies have pointed out a tendency in PHC professionals to provide guidance on obesity only when it is associated with other chronic conditions, which may negatively impact the early identification and follow-up of overweight in older people. A study in Wales showed that PHC professionals delivered regular obesity-related assistance only to patients that had associated comorbidities, for instance hypertension and diabetes mellitus. Additionally, nurses had different opinions on proposing targeted interventions in the absence of comorbidities ${ }^{(26)}$. This perspective points to the invisibility of obesity in clinical practice when it is not associated with chronic conditions.

The participants of the present study verbalized the discontinuity of group actions aimed to treat obesity, which were offered in the past at the BHUs they attended. The cancelled actions were collective activities, carried out by the BHU team or other invited professionals and consisted of providing guidance, essentially on healthy diet, aiming to reduce the patients' body weight.

A study carried out in a BHU in the state of Paraíba, Brazil, showed that most group activities were fragmented and intermittent and were created as a consequence of specific demands of the current administration to meet national targets to the detriment of the population's needs. The main factors that led to the discontinuity of these actions were the prevalence of individual care delivery in the $\mathrm{BHU}$, time restrictions in the team, high employee turnover rate, insufficient knowledge about food and nutrition, and lack of support of the managers. The professionals and users were responsible for the infrastructure used in the collective activities, raising funds from their own resources to pay for them. This situation triggered dissatisfaction in the health team ${ }^{(27)}$.

It is important to emphasize that the methods used to operationalize the group activities were lectures and classes, which concentrate knowledge on health professionals. Controlling obesity calls for interventions that use participatory and dialogic resources to promote the engagement of all the involved people in the activities. This strategy allows to value the exchange of experiences of obese older people. This approach can encourage older people's active participation, motivation, and autonomy ${ }^{(9)}$.

The experiences of obese older people regarding the assistance received in PHC showed a service that is far from ideal for this public, which demands attention concerning physical and cognitive autonomy. Weight measurement must be part of the global evaluation of older people in $\mathrm{PHC}$, and follow-up involves encouraging a healthy diet and physical exercises, considering the specificities of each individual, with the evaluation of risks and benefits. In this context, it is important to emphasize the indispensability of multiprofessional support and the consideration of psychological and motivational aspects involved in obesity and of referrals to the care network according to the necessity ${ }^{(20)}$. 
The efficacy of the interventions is strongly linked to the quality of the relationship developed between obese older people and PHC health professionals, mediated by intersubjectivity. This exchange between users and teams is established mostly by means of the interaction in the care delivered, a moment in which professionals can contribute to the necessary changes in the life habits of obese older people.

Because of their previous subjective experiences, each person has a specific biographical situation, which is defined by how they situate themselves in the life-world. This specific situation is made up of aspects related to the knowledge background built over their concrete existence ${ }^{(15)}$. From this perspective, it proves relevant that $\mathrm{PHC}$ professionals recognize the elements that make up the collection of knowledge of this population, so they can align care to individual needs and expectations, to establish an effective relationship between the health team and obese older people.

The statements also disclosed expectations (reasons for) regarding the assistance provided in PHC, which was oriented toward a qualified longitudinal care and focused on the needs of obese older people. The participants expressed their desire of receiving humanized assistance from the PHC team, mostly because they had obesity and were older people. This service conception can be related to the fact that, as people get older, their relationships tend to be more restricted, and events such as the loss of the partner, the children's moving out, and the thought of the proximity of death can contribute to a higher emotional fragility ${ }^{(28)}$.

The characteristics of chronic diseases, marked by the need of a continuous health care, reinforce the indispensability of a humanized follow-up to older people to prevent complications and increase the engagement of people in self-care. This follow-up must take into account the multifactorial nature and the complexity of chronic health issues in this phase of life, which can be well managed only by resorting to a comprehensive care perspective ${ }^{(29)}$. The specificity of care to obese older people is encompassing the multiple dimensions of individuals, making decisions based on their biological, psychological, and social needs.

Considering the specificities of being an obese older person is fundamental, since the objectives and perceptions of this population regarding overweight differ from those found in a younger population. A systematic literature review found that these conceptions typical of older people emerge from multimorbidity and changes in the perception about aging and health, and that they valued functioning more ${ }^{(30)}$.

Older people expected to receive qualified care, involving professionals that had competence to act according to the specificities of each case. This result reinforces the need to provide PHC professionals with basic training and permanent education, with a specific emphasis on care to obese people at different phases of the life cycle. However, 34 PHC physicians and nurses in England reported in a qualitative study that they did not know how to address the weight subject with obese users and, when they did it, they gave instructions that were not standardized and were influenced by personal beliefs. Some professionals considered inadequate to talk about the weight issue during the appointments, had doubts about the need to treat the patients' obesity, and mentioned lack of knowledge and skills regarding obesity management as a barrier to care ${ }^{(31)}$.
In addition to the fragilities in professional training, there is a lack of policies and guidelines oriented specifically toward care to obese older people. These usually target weight management in the pediatric and adult populations, with no focus on older people. A study carried out in Ghana, Western Africa, found that the national strategy of management of chronic diseases showed directions and targets to reduce the prevalence of overweight and obesity in people from 15 to 49 years old and neglected older people, despite the considerable increase in the disease rate and in life expectancy ${ }^{(32)}$.

The participants of the present study emphasized the relevance of other professionals and resources in PHC to favor weight loss. Given that obesity is a multifactorial disease, coping with it requires multiprofessional work, which was associated with an improvement in quality of life, functional autonomy, and reduced use of health services for cases of acute care to older people with chronic conditions ${ }^{(33)}$. To do that, it is necessary to deepen the knowledge and practices in health care, with emphasis on effective communication and patient-centered care, with their preferences and goals being considered.

In the context of the Brazilian PHC, the BHU health teams can count on the support of the Family Health and Primary Health Care Extended Center (NASF-AB, as per its acronym in Portuguese), whose staff is made up of health professionals from several areas that offer clinical, sanitary, and educational support to the teams that develop their activities in a certain area ${ }^{(34)}$. In the obesity area, these professionals can contribute to expanding and qualifying analysis about the eating and nutritional status of the population, supporting the implementation of actions in this field and even offering individualized and/or group support, in the psychological and emotional sphere and in the guidance on how to practice physical exercises, taking into account the specificities of each person or social group.

A study carried out with professionals and managers from $\mathrm{PHC}$ and food and nutrition technical areas of the 92 municipalities of the state of Rio de Janeiro, Brazil, showed that NASF-AB plays an important role in this context, because it was strongly emphasized by the professionals as a strategy that strengthens $\mathrm{PHC}$ to obese people ${ }^{(35)}$. It is important to stress that, at present, with the new PHC expense funding in Brazil, the arrangement and composition of multiprofessional teams are a responsibility of municipal managers, who do that according to the local needs and characteristics ${ }^{(34)}$, which can reduce the spectrum of activity of PHC to obese older people.

The participants of the present study hoped that the activities of the educational groups previously offered at the BHUs they attended were resumed. This expectation referred to positive experiences these activities offered, which stresses the power of these actions, reaching biopsychosocial aspects found in obesity in older population. A study involving health professionals who developed their activities in $\mathrm{PHC}$, managers, and older people in Rio de Janeiro, Brazil, emphasized that educational groups were a social interaction mechanism that provided benefits to the physical and mental health of the older population. When exchange of experiences is allowed, the social isolation to which many older people are submitted is reduced, leading to the strengthening of community bonds. Additionally, collective actions contribute to promoting self-care and healthy life habits, which are fundamental to control chronic diseases ${ }^{(36)}$. 
The interviewed older people also wanted to receive longitudinal care, identified as an important ally to weight loss. This expectation resulted from the discontinuity of the offered services, which was the current reality of the participants. The role played by $\mathrm{PHC}$ in the follow-up of people with chronic conditions in the context of the Health Care Network must be stressed. This role is closely related to the longitudinality attribute of care, which is the regular offering of care by the same health team over time by means of a humanized and trust relationship between the health team, individuals, and families ${ }^{(37)}$.

By expressing their expectations about obesity-related care, older people resorted to past and present experiences they had in the context of the assistance received in PHC. This aspect shows, in consonance with social phenomenology, that human action is equipped with intentionality and is related to a project in which people find a meaning ${ }^{(15)}$.

The participants hoped that the problems that were limiting the delivery of this service were sorted out so they could have a high-quality care. They emphasized their desire to establish an effective and longitudinal relationship with the health team to control their weight. It can be noted that the effectiveness of the actions developed in PHC is strongly associated with the interactions between health professionals and older people and, in this context, intersubjectivity stands out as a fundamental element in the establishment of these relationships.

\section{Study limitations}

Because this was a qualitative study, its results are evidence specific to the examined group, which belonged to a reality that can be different from others. This hinders generalization of the results and, consequently, other research possibilities must be considered and implemented.

\section{Contributions to nursing, public health, and public poli- cies areas}

In the health system macromanagement sphere, the present study pointed to critical issues that must be included in the agenda of discussions about public policies oriented toward older people, such as the failure to comply with the operationalization of a line of care targeting obesity in this life stage.

The presence of this population in PHC to control other noncommunicable chronic diseases also put the spotlight on the negligence with the disease under discussion in the present study and the need for the body responsible for organizing care in the Health Care Network to increase the clinical management of obesity.
For nursing professionals, who usually assume the leadership role in PHC health teams, the present study marked out the importance of encouraging the design of inducing strategies that encompass planning and incorporation of interprofessional health practices oriented toward obese older people in the micropolicy sphere, making the interventions specific and comprehensive to meet the care needs and expectations shown by these users.

\section{FINAL CONSIDERATIONS}

Alfred Schütz's social phenomenology allowed to show that the experiences of obese older people regarding the assistance received in $\mathrm{PHC}$ were pervaded by fragilities in the actions oriented toward treating obesity. When these actions happened, they were based on prescriptive directions that pointed to the need to lose weight to control other chronic diseases. Additionally, the experiences of the participants touched on the subject of discontinuity of group activities oriented toward weighting loss and developing healthy life habits, which were previously offered in the BHUs they attended in their neighborhoods and were cancelled.

The study also disclosed the expectations of the examined group, which were related to the desire to receive humanized and qualified care from a multiprofessional team, so their specificities were considered. The interviewed obese older people mentioned the wish that new educational groups were formed and that they could receive longitudinal care to lose weight.

The results raise a reflection on care to obese older people in a scenario in which comprehensive and longitudinal care is difficult to achieve. In addition, the instability in the consolidation of public policies, especially in $\mathrm{PHC}$, requires that this care level takes on the responsibility for care coordination, with effective bonds between the services that make up the Health Care Network and between professionals and users.

It is expected that the results of the present study can be used as resources to define the practices of health teams, including the nursing one, which deals with obese older people in $\mathrm{PHC}$, and promote discussions about this subject in the context of training and permanent education of professionals. Additionally, new studies on the subject may address other aspects that will add value to public health and gerontological nursing.

\section{ACKNOWLEDGMENT}

To the National Council for Scientific and Technological Development - Brazil (CNPq, as per its acronym in Portuguese) for granting a research productivity grant to the author Miriam Aparecida Barbosa Merighi.

\section{REFERENCES}

1. United Nations (UN). World population prospects 2019: highlights[Internet]. New York.. 2019 [cited 2020 Apr 28]. Available from: https:// population.un.org/wpp/Publications/Files/WPP2019_Highlights.pdf

2. World Health Organization (WHO). Noncommunicable diseases progress monitor 2020[Internet]. WHO: Geneva. 2020 [cited 2020 Apr 28]. Available from: https://www.who.int/publications-detail/ncd-progress-monitor-2020 
3. Malta DC, Bernall RTI, Lima MG, Araújo SSC, Silva MMA, Freitas MIF, et al. Noncommunicable diseases and the use of health services: analysis of the National Health Survey in Brazil. Rev Saude Publica. 2017;51(suppl 1):1-10. doi: 10.1590/s1518-8787.2017051000090

4. Obesity Collaborators. Health effects of overweight and obesity in 195 countries over 25 years. N Engl J Med. 2017;377:13-27. doi: 10.1056/ NEJMoa1614362

5. Boateng GO, Adams EA, Boateng MO, Luginaah IN, Taabazuing MM. Obesity and the burden of health risks among the elderly in Ghana: a population study. PLoS One. 2017;12(11):e0186947. doi: 10.1371/journal.pone.0186947

6. Rossi-Izquierdo M, Santos-Pérez S, Faraldo-Garcia A, Vaamode-Sánchez-Andrade I, Gayoso-Diz P, Del-Rio-Valeiras M, et al. Impact of obesity in elderly patients with postural instability. Aging Clin Exp Res. 2016;28(3):423-8. doi: 10.1007/s40520-015-0414-4

7. Manrique-Espinoza B, Moreno-Tamayo K, Téllez-Rojo Solís MM, De la Cruz-Góngora VV, Gutiérrez-Robledo LM, Salinas-Rodríguez A. Shortterm effect of physical activity and obesity on disability in a sample of rural elderly in Mexico. Salud Publica Mex. 2014;56(1):4-10. doi: 10.21149/spm.v56i1.7317

8. Ahmadi SM, Keshavarzi S, Mostafavi SA, Bagheri Lankarani K. Depression and obesity/overweight association in elderly women: a community-based case-control study. Acta Med Iran [Internet]. 2015 [cited 2020 Apr 28];53(11):686-9. Available from: https://www.ncbi. nlm.nih.gov/pubmed/26786989

9. Isla Pera P, Ferrér MC, Nuñez Juarez M, Nuñez Juarez E, Maciá Soler L, Lóoez Matheu C et al. Obesity, knee osteoarthritis, and polypathology: factors favoring weight loss in older people. Patient Prefer Adherence. 2016;10:957-65. doi: 10.2147/PPA.S92183

10. Westphal C, Doblhammer G. Projections of trends in overweight in the elderly population in Germany until 2030 and international comparison. Obes Facts. 2014;7(1):57-68. doi: 10.1159/000358738

11. König HH, Lehnert T, Brenner H, Schöttker B, Quinzler R, Haefeli WE, et al. Health service use and costs associated with excess weight in older adults in Germany. Age Ageing. 2015;44(4):616-23. doi: 10.1093/ageing/afu120

12. Braga VAS, Jesus MCP, Conz CA, Silva MH, Tavares RE, Merighi MAB. Actions of nurses toward obesity in primary health care units. Rev Bras Enferm. 2020;73(2):e20180404. doi: 10.1590/0034-7167-2018-0404

13. Tavares RE, Camacho ACLF, Mota CP. Nursing actions to the elderly in the family health strategy: Integrative review. Rev Enferm UFPE. 2017;11(2):1052-61. doi: 10.5205/reuol.10263-91568-1-RV.1102sup201722

14. Ministério da Saúde (BR). Conselho Nacional de Saúde. Resolução no 466, de 12 de dezembro de 2012 [Internet]. 2012 [cited 2020 Apr 28 ]. Available from: https://conselho.saude.gov.br/resolucoes/2012/Reso466.pdf

15. Schütz A. Sobre fenomenologia e relações sociais. Petrópolis: Vozes; 2012. 357 p.

16. Tong A, Sainsbury P, Craig J. Consolidated criteria for reporting qualitative research (COREQ): a 32-item checklist for interviews and focus groups. Int J Qual Health Care. 2007;19(6):349-57. doi: 10.1093/intqhc/mzm042

17. Instituto Brasileiro de Geografia e Estatística (IBGE). População estimada por município [Internet]. 2019 [cited 2020 Apr 28]. Available from: https://cidades.ibge.gov.br/brasil/mg/juiz-de-fora/panorama

18. Secretaria Municipal de Saúde de Juiz de Fora. Plano Diretor da Atenção Primária em Saúde: Projeto de Implantação [Internet]. 2014 [cited 2020 Apr 28]. Available from: https://www.pjf.mg.gov.br/secretarias/ss/plano_diretor/docs/implantacao.pdf

19. Ministério da Saúde (BR). Informação e gestão da Atenção Básica. Cobertura da Atenção Básica [Internet]. 2019 [cited 2020 Apr 28]. Available from: https://egestorab.saude.gov.br/paginas/acessoPublico/relatorios/relHistoricoCoberturaAB.xhtml;jsessionid=2XUMewYlexeis+BO5OudnxKE

20. Ministério da Saúde (BR). Estratégias para o cuidado da pessoa com doença crônica. Obesidade [Internet]. Cadernos de Atenção Básica, nº 38. Brasília; 2014. [cited 2020 Apr 28]. Available from: http://bvsms.saude.gov.br/bvs/publicacoes/estrategias_cuidado_doenca_cronica_ obesidade_cab38.pdf

21. Guerrero-Castañeda RF, Menezes TMO, Ojeda-Vargas MG. Characteristics of the phenomenological interview in nursing research. Rev Gaúcha Enferm. 2017;38(2):e67458. doi: 10.1590/1983-1447.2017.02.67458

22. Minayo MCS. Amostragem e saturação em pesquisa qualitativa: consensos e controvérsias. RPQ [Internet]. 2017 [cited 2020 Apr 28];5(7):112. Available from: https://edisciplinas.usp.br/pluginfile.php/4111455/mod_resource/content/1/Minayosaturacao.pdf

23. Jesus MCP, Capalbo C, Merighi MAB, Oliveira DM, Tocantins FR, Rodrigues BMRD et al. The social phenomenology of Alfred Schütz and its contribution for nursing. Rev Esc Enferm USP. 2013;47(3):736-41. doi: 10.1590/S0080-623420130000300030

24. Ferreira MCS, Negri F, Galesi LF, Detregiachi CRP, Oliveira MRM. Monitoramento nutricional em unidades de Atenção Primária à Saúde. Rasbran [Internet]. 2017 [cited 2020 Apr 28];8(1):37-45. Available from: https://www.rasbran.com.br/rasbran/article/download/227/156

25. Nogueira LR, Morimoto JM, Tanakac JAW, Bazanelli AP. Avaliação qualitativa da alimentação de idosos e suas percepções de hábitos alimentares saudáveis. J Health Sci. 2016;18(3):163-0. doi: 10.17921/2447-8938.2016v18n3p163-70

26. Phillips K, Wood F, Kinnersley P. Tackling obesity: the challenge of obesity management for practice nurses in primary care. Fam Pract. 2014;31(1):51-9. doi: 10.1093/fampra/cmt054

27. Vasconcelos ACCP, Magalhães R. Práticas educativas em Segurança Alimentar e Nutricional: reflexões a partir da experiência da Estratégia Saúde da Família em João Pessoa, PB, Brasil. Interface. 2016;20(56):99-110. doi: 10.1590/1807-57622015.0156

28. Lubenow JAM, Silva AO. What the elderly think of the care provided by health services. Rev Bras Geriatr Gerontol. 2019;22(2):e180195. doi: 10.1590/1981-22562019022.180195 
29. Veras RP, Oliveira MR. Aging in Brazil: the building of a healthcare model. Cienc Saúde Colet. 2018;23(6):1929-36. doi: $10.1590 / 1413-81232018236.04722018$

30. Batsis JA, Zagaria AB.. Addressing obesity in aging patients. Med Clin North Am. 2018;102(1):65-85. doi: 10.1016/j.mcna.2017.08.007

31. Blackburn M, Stathi A, Keogh E, Eccleston C. Raising the topic of weight in general practice: perspectives of GPs and primary care nurses. BMJ Open. 2015;5(8):1-10. doi: 10.1136/bmjopen-2015-008546

32. Lartey ST, Magnussen CG, Si L, Boateng GO, de Graaff B, Biritwum RB, et al. Rapidly increasing prevalence of overweight and obesity in older Ghanaian adults from 2007-2015: evidence from WHO-SAGE Waves 1 \& 2. PLoS One. 2019;14(8):e0215045. doi: 10.1371/journal. pone.0215045

33. Gill LE, Bartels SJ, Batsis JA. Weight management in older adults. Curr Obes Rep. 2015;4(3):379-88. doi: 10.1007/s13679-015-0161-z

34. Ministério da Saúde (BR). Nota técnica no 3/2020 [Internet]. Brasília; 2020 [cited 2020 Apr 28]. Available from: https://www.conasems.org. br/wp-content/uploads/2020/01/NT-NASF-AB-e-Previne-Brasil.pdf

35. Burlandy L, Teixeira MRM, Castro LMC, Cruz MCC, Santos CRB, Souza SR, et al. Modelos de assistência ao indivíduo com obesidade na atenção básica em saúde no Estado do Rio de Janeiro, Brasil. Cad Saúde Pública. 2020;36(3):e00093419. doi: 10.1590/0102-311x00093419

36. Shenker M, Costa DH. Advances and challenges of health care of the elderly population with chronic diseases in Primary Health Care. Cien Saude Colet. 2019;24(4):1369-80. doi: 10.1590/1413-81232018244.01222019

37. Mendes EV. Desafios do SUS [Internet]. Brasília; 2019 [cited 2020 Apr 28]. Available from: http://www.conass.org.br/biblioteca/ desafios-do-sus/ 